\title{
Fall Break Fallout: Exploring Student Perceptions of the Impact of an Autumn Break on Stress
}

\author{
Michael Agnew \\ Conestoga College, Kitchener, Canada \\ Heather Poole \\ University of Ottawa, Ottawa, Canada \\ Ayesha Khan \\ McMaster University, Hamilton, Canada
}

\begin{abstract}
The mental health of post-secondary students has dominated recent discourse surrounding higher education. Accordingly, many institutions have introduced a break in the fall term, designed to support student well-being. As part of an interdisciplinary, longitudinal study examining the effects of the fall break on student stress, we held focus groups with undergraduates. We observed mixed feedback surrounding this intervention. Students appreciated the fall break as an opportunity to reduce their stress, yet they frequently reported negative impacts of the break on the timing of academic assessments and their ability to effectively manage study time. Based on extensive dialogue with students, we provide recommendations for institutions which have implemented or are considering implementing a fall break as a way to support student mental health. We aim to address the paucity of qualitative research on student stress and develop a deeper understanding of the factors driving students' responses to stress intervention policies.
\end{abstract}

Keywords: Mental health; time management; stress; assessment

\section{Introduction}

A recent op-ed written for the Canadian higher education magazine University Affairs began by posing a simple, yet salient question regarding student mental health in higher education: "Why are so many university students struggling?" (Munn, 2019). Indeed, this question has increasingly preoccupied higher education discourse, and has received considerable press coverage over recent years (e.g., Chiose, 2016; Rushowy, 2017). Concern is undoubtedly warranted. Extensive empirical evidence points to the prevalence of stress and mental illness among postsecondary students, rates of which are rising worldwide (Booth, Sharma, \& Leader, 2016; Francis \& Horn, 2017; Ibrahim, Kelly, Adams, \& Glazebrook, 2013; Stallman, 2010). In concert with these findings, a 2016 report assessing mental health and well-being in over 43,000 students across 41 Canadian post-secondary institutions revealed that students are reporting startling levels of stress and mental health concerns. A total of $60 \%$ of respondents had felt hopeless within the past 12 months, $90 \%$ felt overwhelmed, $88 \%$ felt exhausted, $65 \%$ felt overwhelming anxiety, and $13 \%$ had seriously considered suicide. Students reported that the top four factors impacting their academic performance were stress, anxiety, sleep difficulties, and depression (American College Health Association, 2016).

This work is licensed under a Creative Commons Attribution 4.0 International Licence. As an open access journal, articles are free to use with proper attribution. ISSN: 2205-0795 
Post-secondary institutions have been exploring broader structural changes to address student stress and mental well-being. One common intervention among Canadian institutions is the introduction of a multi-day break in the fall (autumn) academic term (Campbell, 2015; Cormack, 2018; MacAlpine, 2018). While a week-long winter break in mid-February is a common and long-standing practice, the trend towards the adoption of a break during the fall term (September to December) has accelerated recently (Campbell, 2015; Irish, 2013). In October 2015, a full-week fall break was introduced McMaster University, a midsized, research-intensive university located in Hamilton, Canada. The break was introduced to provide "students with meaningful reprieve during a strategic moment in the course of their studies to improve academic performance and mental health and well-being" (McMaster University, 2015).

Some universities have reported internal evaluations of students' perceptions of a fall break (e.g. Pilato, 2014) yet there remains limited research on the topic (although see our work cited below, as well as Cramer \& Pschibul, 2017; Hulls, Rennick, Robinson, \& Mohamed, 2018). Given the increasing adoption of fall breaks, it is critical to investigate the broader impact and the efficacy of this as a stress-reduction intervention, so as to support the development of evidence-based policy in higher education. As such, we are a multi-institutional team of researchers examining the effect of the fall break on undergraduate students in an interdisciplinary fashion: by administering validated perceived stress scales and questionnaires exploring undergraduate stress (Poole, Khan, \& Agnew, 2018), by assessing physiological indicators of stress in students (Khan, Poole, \& Beaton, 2018), and by conducting semi-structured focus groups with students. The qualitative branch of the study (presented here) is particularly critical for fostering a deeper understanding of the experiences that students have surrounding the fall break (Schonfeld \& Farrell, 2009). Furthermore, there is a dearth of qualitative work investigating stress, with a recent review of the literature finding that only 1-3\% of published research on stress uses a qualitative approach (Hurst, Baranik, \& Daniel, 2013). Here, we aim to address the paucity of qualitative research on stress, develop a deeper understanding of factors involved in students' responses to stress intervention policies, and explore the impact of the fall break as a solution to student stress and academic needs.

\section{Methods}

During the Fall 2015 and 2016 academic terms, all undergraduate students at our university $(\mathrm{N}=25$, 185) were invited to participate in a two-part survey focusing on perceived stress. The survey was administered in the week immediately prior to and the week immediately after a week-long fall break (see Poole, Khan, \& Agnew, 2017 for full details of survey). Students who participated in the surveys could consent to receive an email invitation to participate in a focus group meant to further explore their experience of the fall break. In 2015 and again in 2016, 125 participants were randomly selected from those who had consented to be contacted, and they were asked to sign-up for one of 50 available focus group slots. Of those contacted in 2015, 42 participated in one of five focus group sessions held; in 2016, 27 participated in one of four focus group sessions. Focus groups were held in a private meeting room on the university campus. They were facilitated by a member of the research team (the lead author) and lasted approximately 45 to 60 minutes in length. All focus groups were audio recorded with a digital recorder (with participants' permission) to ensure accuracy and were later transcribed verbatim for subsequent analysis. The focus group script was open-ended and semi-structured; this provided an opportunity for participants to contribute perspectives about their experience of the fall break that were not anticipated by the research team. This research was approved by the Research Ethics Board at McMaster University, conforming to standards of ethical conduct in research involving human participants.

Transcripts were analysed via a hybrid structured and open coding process (Miles \& Huberman, 1994; Thornberg, 2012). We initiated the coding process with a list of keywords and short phrases that were defined according to our research aims. This was a provisional coding designed to establish an initial list of codes prior to a closer analysis of the focus group transcripts. This initial list of codes was then linked to the script used for the focus groups, and members of the research team collaborated to produce a first coding of the two focus group transcripts using the provisional list of codes. Each researcher then began to code all focus group transcripts, working collaboratively. During this process, new codes were added to the initial list as patterns based on repeated ideas, concepts, or elements began to emerge, and the researchers assessed their codes for inter-rater reliability. A qualitative data analysis software program (NVivo) was used to classify, sort, and arrange information and to examine relationships in the data. 


\section{Results}

Frequency analysis of the focus group transcripts indicated that students were mixed in their assessment of whether the fall break was effective in reducing their perceived stress and helping them manage their academic workload. In all nine focus groups, students reported that they welcomed the additional time spent at home with family and friends during the Canadian Thanksgiving holiday, which occurs on the second Monday in October, typically in the fifth week of the fall term. They also appreciated the opportunity to rest and recover with leisure activities and to catch up on coursework. Yet students frequently reported a negative impact of the fall break on the timing of academic assessments and their ability to effectively manage study time. Furthermore, many students struggled with transitioning between academic responsibilities and break time so early in the semester. The various focus group themes are explored in detail below.

Table 1

Six major themes that emerged from focus group analyses

\begin{tabular}{|l|l|}
\hline \multicolumn{1}{|c|}{ Benefits } & \multicolumn{1}{c}{ Challenges } \\
\hline A. Recuperation and stress reduction & A. Impact on density of assessments \\
B. Opportunity for academic work & B. Time management during the fall break \\
& C. Disruption of academic routine \\
& D. Timing of the fall break \\
\hline
\end{tabular}

\section{Benefits of the Fall Break}

\section{A. Recuperation and stress reduction.}

Policy-makers frequently tout the fall break as a method to reduce student stress. In line with this, several students reported that the break provided them with a meaningful reprieve from their academic commitments and relieved some stress which had been building since the beginning of the term. Furthermore, some participants observed that the break offered a window for broader physical recuperation, allowing them to recover from significant sleep deprivation and physical illness over the preceding weeks. One student described the fall break as vital to restoring her general well-being after an already stressful first month of the term:

The fall break was extremely, extremely... it was life-saving important because the week before and the week after was packed with assignments and midterms, and I was lacking so much sleep at night. I was so stressed out from the previous week. If I didn't have that one week off, and I just kind of jumped right to the next week, I don't know what would have happened to me (probably go crazy), but I did have that kind of buffer week. I was able to like, step out of the stress that I had and kind of just relax and kind of fix myself before I jumped back in (focus group 3).

Students perceived the fall break as an essential opportunity to attend to their emotional and mental well-being, which was often compromised by their academic schedules. Another student's reflections on the fall break as a resource for managing her mental health are representative of this:

I would say that October is usually the month, from knowledge of previous school years, when I have a full-blown mental breakdown and I cannot function and something goes wrong and I flunk a mid-term. So having the week to catch my breath, it was such a weight off my chest, it made...Me and my friends always used to describe October as the 'Hell Month,' and it made it way less of a 'Hell Month' (focus group 2).

Furthermore, the fall break is a period in the academic year when students can focus on restoring their physical health. In some cases, students believed that university life impeded their ability to recover from physical illness, as articulated by one participant: 
For me, because I didn't have anything due the weeks after the fall break, it was mainly decompressing, relaxing, trying to just calm down and de-stress. I felt like I did that. I was also sick, like really sick, the week before so I was still weak and getting over that during the week before. The fall break allowed me time to actually get better and get back on my feet before school started again (focus group 6).

Together, students' narratives regarding high levels of self-perceived stress indicate that the fall break can be a critical opportunity to obtain much-needed rest in order to continue functioning throughout the remainder of the term.

\section{B. Opportunity for academic work.}

In addition to providing an opportunity for stress reduction and physical recovery, a minority of students indicated that the fall break afforded them the opportunity to devote more time to their academic work, without the distraction of classes. One student noted:

I got done all of the work that I needed to have done. On the overdue assignments and the assignments that were due in the next week, and then studied for midterms as well. Then I had some things that I could've done, like future assignments due two to three weeks in the future that I didn't end up doing (focus group 4).

Other students observed that the break gave them an entire uninterrupted week to focus on preparing for a number of midterm exams and other assignments that were scheduled immediately following their return to campus. The general consensus from these students was that this improved their overall academic performance and their ability to manage competing deadlines.

\section{Challenges Associated with the Fall Break.}

\section{A. Impact on density of assessments.}

The above comments from students illustrate that the fall break did indeed have some success in achieving the positive outcomes that were anticipated by university administrators when the break was first introduced. However, our findings suggest that the reach of these positive outcomes may be limited by the impact of the fall break on the timing of academic assessments. When asked about this, some students reported no discernible impact on their course schedule. The prevailing perception, however, was that there was a clear compression of assessments either immediately before or immediately after the fall break. Students reported that this caused feelings of being overwhelmed, anxious, and stressed, and perceived consequent impacts on their overall well-being and academic performance.

When discussing the compression of assessments in the weeks surrounding the break, students often speculated as to the underlying rationale for instructors' scheduling of assignment deadlines and exam dates. Some assumed that instructors compressed assessments before the break so that students would use the week to de-stress and recover, while others believed instructors wished to use the fall break to grade assignments. In some cases, students reported that instructors were quite explicit in detailing their approach, as one student noted regarding a perceived compression of assessments prior to the break:

Because of the placement of the reading week, one professor specifically said that he moved that midterm up, and it was to the point that some of my friends in my program had three midterms on one day that would have otherwise been staggered. I had a midterm, another midterm, and a presentation within a twenty-four hour period during that week before. It was a very, very stressful week so I needed a lot more time than I initially realized to decompress [during the break] rather than getting ahead which actually didn't happen at all, unfortunately (focus group 6).

Comments from this student indicated that although the week immediately before the break was overwhelming, he found the opportunity to use the fall break to, in his words, "decompress." However, he also expected to make progress on upcoming assignments during the break but found this impossible given the need to recover from the stress of the week before. Thus, his assessment of the benefits of the fall break was, like several students, mixed. A similar experience is echoed by another student:

\footnotetext{
I had to do all of my assignments and two midterms the week before [the break] and I thought that I was two weeks behind, then two weeks ahead, and then come a week later, I'm a week behind again. It's all kind of that illogical shift. I kind of really struggled and I still am struggling to catch up with the fallout from this fall break (focus group 4).
}

Although it was not common, the term "fallout" arose organically in three separate focus groups to describe the impact of the fall break. While the term "fallout" may seem a bit histrionic, it reflects the cascading negative impact of the break that some 
students perceived, especially around the compression of assessments. This is illustrated by another student who described the compression of assessments immediately following the break:

The week after, especially this year was the most stressful week of the semester. I had several midterms and assignments that week. I finished the week and I realized that I had gotten more behind on the things that were due the next week because not having accomplished what I wanted to over the fall break made me more stressed. Now I am back on track, but I think being on the fall break contributed to the stress (focus group 8).

Rather than the fall break affording a much-needed opportunity to de-stress and catch up on school work, students were likely to fall further behind and feel more stressed and overwhelmed by competing assignment deadlines and exams. Another student referred to what she perceived to be the motives informing instructors' decisions around assessment scheduling, this time in reference to the week following the break:

After the reading break it seemed like every single one of my professors had decided to push things back instead of bring them forward. I think maybe they thought they were doing us an extra favor, like 'We're giving them an extra week,' but it just made things more stressful (focus group 6).

Several students acknowledged that instructors often had good intentions when determining the schedule of assessments, but they observed that when this was not coordinated with departmental colleagues, it led to a severe compression of assessments. This seemed particularly true after the break, and was stressful for many students. Any potential stress reduction from the fall break was quickly dissolved as students transitioned back to campus and an additionally hectic pace of classes and deadlines resumed.

\section{B. Time management during the fall break.}

Given the perceived compression of assessments in the week immediately following the fall break, several students discussed the need to use the break effectively as a vehicle for catching up on neglected schoolwork or to study in anticipation of midterm exams and other assessments that were scheduled immediately following their return to campus. Again, a minority of students found that the fall break was effective in allowing them the space to catch up on schoolwork; instead, most reported that it was not at all conducive to effectively managing their time. In fact, the break often encouraged procrastination, making the transition back to campus afterwards all the more difficult. As one student observed, relaying his own experience as well as that of peers he had spoken to about the fall break:

I've spoken to people who've said that being given a whole week gives you more time to procrastinate. So, it's a very common trait, sometimes getting an extra week does not compensate for the level of work because most people don't use their time effectively. The more time you're given, the more time you take (focus group 9).

Across all focus groups, several students concurred that while they appreciated having a week away from campus and an opportunity to de-stress, that it was difficult to accomplish their plans to use at least part of the fall break period to focus on their studies. Often, it was not until the Saturday or Sunday before returning to campus that students would begin to refocus on their studies; this caused stress and a sense that they did not do enough over the break. Interestingly, even when students did plan to take some much-needed time off from their studies during the break, they often reported a constant underlying pressure to be productive:

\footnotetext{
I do think the break is beneficial and is seen as a mental health thing, but sometimes it's hard to even enjoy it because you know you're supposed to be working throughout the week... the social pressure or things your profs say, like 'Oh, make sure you're doing your readings during the fall break' kind of thing. For me it was one of those things where even if I was relaxing, it felt like I should be doing something. Because it's like 'Oh you have a whole week, you should be doing these things.' Even though I did work, even coming out of it, a part of me was like 'Did I do enough?' (focus group 7).
}

Linked to this question of whether one had been sufficiently productive during the week is an acute sense of guilt and regret. Some students were particularly explicit regarding the guilt they felt for not managing their time effectively, not meeting goals they had set for the break, and ultimately returning to campus overwhelmed by a crunch of exams and assignment due dates. For example:

I think just the idea of a fall break gives you so many expectations and when you fall short, you think 'Wow, I'm a failure, like what did I do with my time?' Sometimes you end up feeling bad for sitting on your couch doing nothing, but then you actually 
realize that you really need to sit on your couch and do nothing. We're so used to powering through everything sometimes, that it's nice to be able to just sleep in. But at the same time, it stresses you out even more, because you end up with so much to do, and you're like you should be doing something (focus group 8).

For some students then, contrary to expectations, the fall break not only failed to meaningfully reduce stress, but in fact amplified it.

\title{
C. Disruption of academic routine.
}

Following from this, when students were asked what in particular hindered their ability to effectively manage their time and allow them to focus on their studies during the fall break, several described the break as being highly disruptive of their academic routine. While they appreciated the opportunity to relax and visit with their family and friends, they perceived that the break had upset their "natural rhythm" (focus group 8) and that, as one student stated, it "really took me off my game" (focus group 5). The concept of momentum having been lost as a result of the fall break recurred in many students' comments:

\begin{abstract}
I have a sort of momentum that I develop over the course of a semester where I set things aside and just get really focused on my academics. I consider academics to be a huge part of my life and I enjoy doing well and I try to do well as much as I can. Whenever I take extended breaks from my academics, my momentum obviously derails and it's a little bit of a harder time to get motivated back up again and start really putting the nose to the grindstone, because I realize that 'Oh, wait, it's so much fun to not be doing this' (focus group 4).
\end{abstract}

Clearly, as students returned to campus after the break and began to transition back into the academic routine, it was difficult to regain the motivation to focus on their academic tasks to the degree that they once had. Another student stated the desire to be back on campus and back into the structure of their course schedule:

I cannot work, whether it's at my house in Hamiltonor at my home elsewhere, with my family. Just the setting does not mesh well with my ability to concentrate. Whether it's that I have distractions because of roommates or I want to spend time with my family and friends. Whenever I do need to get stuff done, or I really need to work, I'm always on campus. It's almost like I separate my home, social life, and then my work, campus life. I feel like that might've been a factor as to why my goals were not entirely met, is that I couldn't be around McMaster, around campus to have that work aspect (focus group 4).

This excerpt reflects the sentiment of several students that, even if the break was effective for them as a stress reduction tool, the setting of the fall break was not conducive to sustained academic work. This highlights the importance of optimal and familiar study conditions in fostering the level of focus necessary for academic work. While the fall break provides time for academic work, this time is experienced in a setting that does not typically involve academic work. Thus, while students acknowledged their difficulty in managing their time effectively over the break, and conceded that in many cases they simply procrastinated, the disruption of their campus-based lifestyle was also a significant factor.

\section{Timing of the fall break.}

Concomitant with concerns regarding the disruptive nature of the fall break were opinions about the timing and length of the fall break. Currently, the fall break period at our university is scheduled for the second week of October (to align with the Canadian Thanksgiving holiday). This is five weeks after classes begin. Some students appreciated this, noting that from a logistical perspective it made sense to schedule the break during the week of Thanksgiving, when only four instructional days would be lost instead of five, and when it would facilitate students travelling for the holiday. Nonetheless, many observed that the scheduling of the break early in the academic term and coinciding with the Thanksgiving holiday limited the potential benefits of the break in reducing student stress and supporting academic success:

I think the placement of the reading week was just too early for me to even gauge where my academic commitment was. It was only five, six weeks in. I didn't have a lot of stuff before the week. It was me basically basing everything off the week after and because I was so stressed already, I felt like I wasn't doing as well as I could have... I think I would have appreciated it being pushed back a little bit more so that I could gauge where I was. I had no marks, I didn't know my academic standing prior to the reading week. I had no marks back. It was hard to gauge what I had to do over the week to either bring my mark up or maintain (focus group 6).

Several students echoed the above excerpt in calling for the fall break to be pushed later in the term, indicating that it would be preferable to hold it in late October or early November. A break scheduled during this time would more evenly divide the term, 
and the mid-way point of the term naturally tends to be more hectic with midterm exams. Another suggestion was to hold the fall break in the week immediately preceding the final exam period in early December, as this would give students a reprieve from their coursework and assessments and an opportunity to prepare for their final exams at a time when they were less likely to travel away from campus.

Perhaps surprisingly, in addition to a break scheduled later in the term, some students indicated a preference for a shorter break, noting that they found the existing full-week break to be too long and as a result counter-productive. For example,

A long weekend is much more useful, I mean personally, to get some studying done, get some relaxing done, but not lose that momentum. Rather than having a full week, going home for the week, and setting a list of things to do and just getting distracted by Netflix or whatever else. (focus group 3).

This perspective reflects a common perception that the full-week fall break disrupted academic momentum, thereby inhibiting effective time management strategies and facilitating procrastination.

\section{Discussion}

Despite a broad consensus among post-secondary administrators and student union representatives that a fall break will reduce student stress and support mental well-being, our study indicates that the outcomes of this policy intervention are in fact far more nuanced. Certainly, students in our focus groups reported that they appreciated having the fall break as an opportunity to reduce stress, rest, and recover from a hectic start to the school year. At first consideration, this finding seems paradoxical in light of longitudinal survey results from the broader student population at our institution (see Poole, Khan, \& Agnew, 2017; Poole, Khan, \& Agnew, 2018; Khan, Poole, \& Beaton, 2018), which revealed that perceived stress was significantly higher after the break than before it. However, discussions with focus group participants revealed underlying reasons for this and provided critical context regarding the student experience that was not available from more quantitative measures.

Students' reports of the transition back to campus after the break indicated that their post-break stress heavily derived from overwhelming academic responsibilities upon returning to campus. This finding supports other research indicating that one of the most prevalent stressors for students is academic assessments, especially when many of them are scheduled within a compressed time period (Hurst, Baranik, \& Daniel, 2013; Misra \& McKean, 2000; Murphy \& Archer, 1996). Students in our sample were facing this common challenge under the additional pressure of a sense of guilt or failure surrounding procrastination and ineffective time management during the break. Research on academic procrastination is replete with reports of such responses to unobtained academic goals and ineffective management of academic-based stressors (Howell \& Watson, 2007; Krause \& Freund, 2014; Wohl, Pychyl, \& Bennett, 2010).

Our results also showed that many students felt that the fall break interrupted the momentum of their school year, and that the change in setting made it difficult to study over the break and to transition back to schoolwork. This sense of momentum is similar to the concept of flow, which is a state of fluid productivity that can emerge when levels of skill are balanced with the challenge of the situation (Csikszentmihalyi, 1991). When challenge is too high for a given skill level, individuals experience anxiety; when challenge is too low, they experience boredom. Since flow is associated with academic performance (Sumaya \& Darling, 2018) and student engagement (Shernoff, Csikszentmihalyi, Schneider, \& Shernoff, 2003), this is a factor that could have lasting impacts on students' learning. Our conversations with undergraduate students indicate that they were at a balanced level of challenge and skill before the break, allowing them to be more immersed and engaged with their studies at this time point. The break not only interrupted this immersion, but also produced an imbalance where students lacked the requisite skills to navigate the challenge of multiple competing deadlines. Their resulting anxiety reiterates the potential consequences of compression of assessments around the break. Finally, students' reports of stress after the break are consistent with the literature on workplace vacations. Although stress usually drops during vacation, it often increases to pre-vacation levels once an individual resumes work (Syrek, Weigelt, Kühnel, \& de Bloom, 2018); this is especially the case when met with a heavy workload (Strauss-Blasche, Ekmekcioglu, \& Marktl, 2002).

\section{Recommendations and Conclusions}

Given students' concerns regarding the negative impact of the fall break on their stress levels and academics, we suggest the following in order to maximize the efficacy of the break as a stress-reduction intervention. 


\section{Postpone the Fall Break}

Our institution holds the fall break in the fifth week of the fall semester. Holding the fall break at a later point in the semester could serve two functions. Firstly, it may decrease students' sense of lost momentum, as they would be more thoroughly settled into the student lifestyle than they are earlier in the semester. Secondly, placing the break nearer the halfway point in the semester could provide students with a more accurate perspective on how they need to prioritize their time, as they would have some idea of their academic standing in their courses. Given that the fall break is designed as a stress-reduction mechanism for students, we encourage policy-makers to schedule it at a time that is optimal for students. We plan to study students' experience of the winter reading break (scheduled in the seventh week of the semester) to empirically assess the impact of different timings of breaks.

\section{Disperse Assessments}

We imagine two main mechanisms to allow for this. Several institutions implement a test ban around the end of the semester, and some colleges have implemented a test ban immediately before and after the fall break. Taking it a step further, faculties or departments could institute some sort of shared calendar to allow professors to distribute assessments evenly over the semester. While this would no doubt be difficult to implement, we believe it could drastically reduce the challenges students face regarding the fall break.

\section{Conduct Institutional Evaluations of the Fall Break}

The use of fall breaks as a stress-reduction tool has been widely adopted by Canadian universities, with little evidence to support the effectiveness of such an intervention in reducing stress and supporting overall student well-being. Given that universities fulfill a vital social function as sites of research generation, collecting evidence to support the implementation of policies that have an impact on their entire student body should be the norm. The importance of evidence-based policy is perhaps particularly critical in light of the context in which the fall break is presented: the mental health and well-being of students. Our work provides a starting point for internal reviews consisting of working groups in the form of multidisciplinary teams that should include students, staff, and faculty to offer varied perspectives and to assess whether the break is meeting its intended outcomes. Given the Canadian context of this study, a future direction for research in this area might be to seek to replicate our study in other international post-secondary systems, where similar stress-reduction interventions have been employed.

\section{Acknowledgements}

This study was funded by the Canadian Association of College and University Student Services, the Ontario Ministry of Colleges and Universities, and the Arts Research Board at McMaster University. We are grateful for the contributions of Jeremy Sandor, Nathan Cooper, Sean Beaudette, Arpa Modi, Bismah Basharat, Joshua Wiener, Sabrina Campanella, Polina Andrievskaia, and Suad Ali.

\section{References}

American College Health Association. (2016). ACHA - National college health assessment II: Canadian reference group executive summary, Spring 2016. https://www.acha.org/documents/ncha/NCHAII\%20SPRING\%202016\%20CANADIAN\%20REFERENCE\%20GROUP\%20EXECUTIVE\%20SUMMARY.pdf/

Booth, R. W., Sharma, D., \& Leader, T. I. (2016). The age of anxiety? It depends where you look: Changes in STAI trait anxiety, 1970-2010. Social Psychiatry and Psychiatric Epidemiology, 51(2), 193-202. https://doi.org/10.1007/s00127015-1096-0

Campbell, M. (2015, November 19). How to fight the mental health crisis on campus: Fall breaks. Maclean's. https://www.macleans.ca/education/how-to-fight-the-mental-health-crisis-on-campus-fall-breaks/

Chiose, S. (2016, September 8). Reports of mental health issues rising among postsecondary students: Study. The Globe \& Mail. https://www.theglobeandmail.com/news/national/education/reports-of-mental-health-issues-rising-amongpostsecondary-students-study/article31782301/

Cormack, K. (2018, November 1). New fall break starting November 7 to ease student stress and improve mental health. University of Regina. https://www.uregina.ca/external/communications/feature-stories/current/2018/11-011.html/ 
Cramer, K., \& Pschibul, R. (2017). Student time usage during fall reading week. Collected Essays on Learning and Teaching, $X$. https://doi.org/10.22329/celt.v10i0.4754

Csikszentmihalyi, M. (1991). Flow: The psychology of optimal experience. Harper Perennial.

Francis, P. C. \& Horn, A. S. (2017). Mental health issues and counselling services in US higher education: An overview of recent research and recommended practices. Higher Education Policy, 30(2), 263-277. https://doi.org/10.1057/s41307016-0036-2

Howell, A. J., \& Watson, D. C. (2007). Procrastination: Associations with achievement goal orientation and learning strategies. Personality and Individual Differences, 43(1), 167-178. http://dx.doi.org/10.1016/j.paid.2006.11.017

Hulls, C., Rennick, C., Robinson, M., \& Mohamed, S. (2018). Effects of a fall reading break on first year students' course performance in programming. Proceedings of the Canadian Engineering Education Association (CEEA) Conference. 2-8. https://doi.org/10.24908/pceea.v0i0.13006

Hurst, C. S., Baranik, L. E., \& Daniel, F. (2013). College student stressors: A review of the qualitative research. Stress and Health, 29(4), 275-285. https://doi.org/10.1002/smi.2465

Ibrahim, A. K., Kelly, S. J., Adams, C. E., \& Glazebrook, C. (2013). A systematic review of studies of depression prevalence in university students. Journal of Psychiatric Research, 47(3), 391-400. https://doi.org/10.1016/j.jpsychires.2012.11.015

Irish, P. (2013, October 14). Ontario universities embrace mid-term "fall break" to ease students' minds. The Toronto Star. https://www.thestar.com/life/health_wellness/2013/10/14/ontario_universities_embrace_midterm fall_break_to_ease_stu dents_minds.html

Khan, A., Poole, H., \& Beaton, E. A. (2018). Measuring the impact of a weeklong fall break on stress physiology in first year engineering students. The Canadian Journal for the Scholarship of Teaching and Learning, 9(2). https://doi.org/10.5206/cjsotl-rcacea.2018.2.9

Krause, K., \& Freund, A. M. (2014). Delay or procrastination: A comparison of self-report and behavioral measures of procrastination and their impact on affective well-being. Personality and Individual Differences, 63, 75-80. doi:10.1016/j.paid.2014.01.050

MacAlpine, I. (2018, May 3). Queen's adjusts schedule to build in fall break. The Kingston Whig-Standard. Retrieved from https://www.thewhig.com/

McMaster University. (2015, January 15). McMaster approves full week fall break. https://dailynews.mcmaster.ca/articles/mcmaster-approves-full-week-fall-break/

Miles, M. B., \& Huberman, A. M. (1994). Qualitative data analysis: An expanded sourcebook. Sage Publications.

Misra, R., \& McKean, M. (2000). College students' academic stress and its relation to their anxiety, time management, and leisure satisfaction. American Journal of Health Studies, 16(1), 41-51.

Munn, C. (2019, January 7). Why are so many students struggling with their mental health? University Affairs. https://www.universityaffairs.ca/opinion/in-my-opinion/why-are-so-many-students-struggling-with-their-mental-health/

Murphy, M. C., \& Archer, J. (1996). Stressors on the college campus: A comparison of 1985-1993. Journal of College Student Development, 37(1), 20-28.

Pilato, K. (2014). Exploring the impact of a fall break on student mental health outcomes: Year 1 report. https://brocku.ca/webfm/Mental_Health_and_Fall_Break_Report_Year_1-good,_final\%5b2\%5d.pdf

Poole, H., Khan, A., \& Agnew, M. (2017). One week, many ripples: Measuring the impacts of the fall reading week on student stress. Collected Essays on Learning and Teaching, X, 163-171. https://doi.org/10.22329/celt.v10i0.4757

Poole, H., Khan, A., \& Agnew, M. (2018). Stressing in the fall: Effects of a fall break on undergraduate students. Canadian Journal of Higher Education, 48(3), 141-164. https://doi.org/10.7202/1057133ar

Rushowy, K. (2017, October 10). Student mental health needs growing, Ontario colleges say. The Toronto Star. https://www.thestar.com/news/queenspark/2017/10/10/student-mental-health-needs-growing-ontario-colleges-say.html

Schonfeld, I. S., \& Farrell, E. (2009). Qualitative and quantitative methods in occupational-stress research. In A. M. Rossi, J. C. Quick, \& P. L. Perrewe (Eds.), Stress and Quality Working Life (pp. 183-204). Information Age Publishing.

Shernoff, D. J., Csikszentmihalyi, M., Schneider, B., \& Shernoff, E. S. (2003). Student engagement in high school classrooms from the perspective of flow theory. School Psychology Quarterly, 18(2), 158-176. doi:10.1521/scpq.18.2.158.21860

Stallman, H. M. (2010). Psychological distress in university students: A comparison with general population data. Australian Psychologist, 45(4), 249-257. https://doi.org/10.1080/00050067.2010.482109

Strauss-Blasche, G., Ekmekcioglu, C., \& Marktl, W. (2002). Moderating effects of vacation on reactions to work and domestic stress. Leisure Sciences, 24, 237-249. https://doi.org/10.1080/01490400252900176 
Sumaya, I. C., \& Darling, E. (2018). Procrastination, flow, and academic performance in real time using the experience sampling method. The Journal of Genetic Psychology, 179(3), 123-131. https://doi.org/10.1080/00221325.2018.1449097

Syrek, C. J., Weigelt, O., Kühnel, J., \& de Bloom, J. (2018). All I want for Christmas is recovery - Changes in employee affective well-being before and after vacation. Work \& Stress, 32(4), 1-21. https://doi.org/10.1080/02678373.2018.1427816

Thornberg, R. (2012). Informed grounded theory. Scandinavian Journal of Educational Research, 56(3), $243-259$. https://doi.org/10.1080/00313831.2011.581686

Wohl, M. J., Pychyl, T. A., \& Bennett, S. H. (2010). I forgive myself, now I can study: How self-forgiveness for procrastinating can reduce future procrastination. Personality and Individual Differences, 48(7), 803-808. doi:10.1016/j.paid.2010.01.029

\section{Please cite this article as:}

Agnew, M., Poole, H., \& Khan, A. (2019). Fall break fallout: Exploring student perceptions of the impact of an autumn break on stress. Student Success, 10(3), 45-54. https://doi.org/10.5204/ssj.v10i3.1412

This article has been peer reviewed and accepted for publication in Student Success. Please see the Editorial Policies under the 'About' section of the Journal website for further information.

Student Success: A journal exploring the experiences of students in tertiary education

(c) (i) This work is licensed under a Creative Commons Attribution 4.0 International Licence. As an open access journal, articles are free to use with proper attribution. ISSN: 2205-0795 